\title{
CRIANÇAS COM DEFICIÊNCIA E APRENDIZAGEM DE LÍNGUAS ESTRANGEIRAS: CONTRIBUIÇÕES E REFLEXÕES
}

\author{
Marcos Venicio Esper ${ }^{1}$ \\ UEMG - Universidade do Estado de Minas Gerais.
}

\section{RESUMO}

Este ensaio teórico-reflexivo propõe discutir e refletir acerca de crianças com deficiência aprenderem uma língua estrangeira. Deve-se lembrar de que pessoas com deficiência podem apresentar tempos diferentes para elaboração da mensagem e, os receptores - familiares, amigos, escola, profissionais da saúde - devem estar, minimamente, preparados para a decodificação e interpretação. Familiares, profissionais das áreas da educação e da saúde devem ser tradutores dos contextos individuais e subjetivos de jovens com deficiência, quando necessário. $O$ estudo de uma língua estrangeira é uma ferramenta importante não só para fim acadêmico, mas pode trazer benefícios cognitivos, assimilar diferentes culturas, desenvolvimento da memória, habilidades e competências. Para que isso ocorra é preciso pensar na comunicação da família alinhada com a escola e, a escola, por sua vez, alinhada com o jovem. A escola não é importante apenas para a socialização do aluno com deficiência, mas, sobretudo, para a sua constituição como sujeito.

Palavras-chaves: Língua Estrangeira, Linguagem, Inclusão, Pessoas com Deficiência.

\footnotetext{
${ }^{1}$ Mestre em Ciências da Saúde. Passos, Estado de Minas Gerais. Universidade do Estado de Minas Gerais. e-mail: marcos.esper@uemg.br
} 


\title{
CHILDREN WITH DISABILITIES AND FOREIGN LANGUAGE LEARNING: CONTRIBUTIONS AND REFLECTIONS
}

\begin{abstract}
This theoretical-reflective essay proposes to discuss and reflect about children with disabilities to learn a foreign language. It should be remembered that people with disabilities can present different times for the elaboration of the message and that the recipients - family, friends, school, health professionals - must be, at least, prepared for decoding and interpretation. Family members, education professionals, health professionals should be translators of the individual and subjective contexts of young people with disabilities, when necessary. The study of a foreign language is an important tool not only for academic purposes, but can bring cognitive benefits, assimilate different cultures, memory development, skills and competences. For this to happen, it is necessary to think about family communication aligned with the school and, the school, in turn, aligned with the young person. The school is not only important for the socialization of the disabled, but for its constitution as a subject.
\end{abstract}

Keywords: Foreign Language; Language; Inclusion; Disabled People.

\section{Introdução}

Estudar um idioma ocupa um lugar cada vez mais importante na educação em toda a parte do mundo. Não apenas os alunos do ensino regular, os quais quase sempre são obrigados a estudar uma língua estrangeira, mas muitas universidades e escolas de ensino médio adicionaram línguas estrangeiras à grade, como enriquecimento ou requisito. E, é claro, é mais comum do que improvável que universidades exijam a conclusão de estudos de línguas estrangeiras. Para o aluno "não deficiente", às vezes dentro do senso comum conhecido como o "aluno normal", o estudo de línguas estrangeiras é, de fato, uma experiência enriquecedora. Para o aluno com deficiência, no entanto, pode ser uma experiência incrivelmente estressante e humilhante, o oposto do que é esperado, devendo, notadamente, ser um tema de relevante pesquisa.

No campo da educação inclusiva, estudar uma língua estrangeira pode vir a ser um desafio significativo para os alunos com deficiência, fato que tem sido inexplorado no campo da educação (DIAS, 2021).

Portanto, esse fato acrescenta a urgência e a necessidade de olhar para esse tema. À medida que pesquisas estão em andamento e professores reconhecem o problema, soluções são oferecidas ao aluno que enfrenta o desafio de aprender um idioma estrangeiro e para os professores que ensinam.

Para Kobolt \& Mira (2015) pessoas com deficiência têm dificuldades de interação social ou cognitiva, ou seja, possuem limitações. As autoras defendem que essa situação limitada não é um entrave na aprendizagem, mas um desafio, no qual, através de um olhar diferente pode-se investir e acreditar nas capacidades de cada indivíduo com deficiência. As pessoas com deficiência podem realizar atividades tão comuns quanto à de outras pessoas, ainda que com dificuldade e com um tempo diferente. 
Isto posto, considera-se o estudo de idioma uma ferramenta importante não só para fim acadêmico, mas pode trazer benefícios cognitivos, assimilar diferentes culturas, desenvolvimento da memória, habilidades de tomar decisões com mais rapidez (KEYSAR, 2012).

\section{Método}

Trata-se de um ensaio teórico-reflexivo que propõe uma discussão e reflexão acerca de crianças com transtorno mental ou deficiência intelectual aprenderem uma língua estrangeira.

Os estudos utilizados foram artigos e publicações em periódicos referentes à temática, tendo em vista que as publicações acerca da problemática em questão ainda são incipientes. $O$ ensaio teórico tem como fundamentos a exposição lógica e reflexiva, além de uma argumentação com considerável grau de interpretação e julgamento pessoal (SEVERINO, 2002).

\section{Língua e Linguagem e Comunicação}

Autores como Haag (2015) tem se dedicado a estudos sobre a linguagem e sublinham que a Linguística (aplicada ou não), além da área da Educação, nos permite estudar a língua e linguagem dos alunos de forma geral, incluindo os alunos diagnosticados com Inclusão. Para tanto se torna importante definir o que é Língua, Linguagem e Comunicação.

Segundo Saussure (2001), a Língua é uma convenção estabelecida, homogênea e uma produção social, isto é, essencial para a vida humana ao passo que a Linguagem é a faculdade dada pela natureza, a possibilidade de constituir uma língua, heterogênea e pertence a um âmbito multifacetado, isto é, contém aspectos físicos, fisiológicos e psíquicos; pertence ao social e ao individual.

Para Lyons (1987) apud Quadros (2006, p.15), a linguagem é um sistema de comunicação natural ou artificial, humano ou não, portanto, linguagem é qualquer forma utilizada com algum tipo de intenção comunicativa incluindo a própria língua. A aquisição da linguagem se inicia nos primeiros contatos do bebê com o mundo, por meio da interação com o meio e as pessoas ao seu redor. Essa visão entende a linguagem como fenômeno social e cultural, no qual o desenvolvimento vai acontecendo mediante os estímulos e interferências que esse ambiente tem na vida da criança.

O termo comunicação é derivado do latim "communicare", que significa partilhar, tornar comum. Portanto, de acordo com a etimologia, pode-se dizer que a comunicação é o processo por meio do qual um indivíduo pode partilhar informações, pensamentos, histórias, sensações, ideias ou qualquer outra coisa. Para que ocorra o processo de comunicação são necessários seis elementos: Emissor - aquele que envia a mensagem; Receptor ou destinatário - a quem se destina a mensagem; Mensagem - o conteúdo, aquilo que se deseja comunicar; Canal de comunicação - meio de transmissão (TV, rádio, jornal); Código - conjunto de signos e regras sobre os quais a mensagem é elaborada (ex: Língua Portuguesa ou Língua Espanhola); Contexto - situação à qual a mensagem se refere. O emissor elabora uma mensagem de acordo com um contexto, codifica-a e envia para o receptor por meio de um canal de comunicação. $O$ receptor, por sua vez, vai receber essa mensagem, decodificá-la e interpretá-la. Isso costuma acontecer tão rápido, que nem nos damos conta de todas essas etapas, embora elas existam (RESUMO ESCOLAR, 2019).

Vale lembrar que não existe uma linguagem certa. Um aluno que utiliza a língua padrão em seu cotidiano não está mais correto do que alguém que, ao conversar com a família, adota a 
linguagem típica da região em que vive, por exemplo. 0 importante é que haja adequação de acordo com o contexto, lembrando de que há outras compreensões sobre comunicação, como por exemplo, um meio para que se estabeleçam as relações sociais entre os seres humanos, bem como as pessoas com deficiência. A comunicação é imprescindível para a socialização e a compreensão entre as pessoas, na qual as pessoas se comunicam por meio de diferentes maneiras como: escrita, verbal, gestual, corporal, código braile, Língua Brasileira de Sinais (LIBRAS), Comunicação Aumentativa e Alternativa (CAA), entre outras (RICALDI, 2021).

E quando esse processo de comunicação se dá com pessoas com deficiência?

Deve-se pensar que o emissor, com deficiência, pode apresentar tempos diferentes para elaboração da mensagem e, os receptores (familiares, amigos, escola, profissionais da saúde etc.) devem estar, minimamente, preparados para a decodificação e interpretação.

Não entraremos aqui nos contextos das diferentes patologias, transtornos, síndromes etc., pois cada um apresenta suas especificidades.

\section{Caminhos das Dificuldades - Dificuldade de Aprendizado de Idiomas}

Adquirir uma segunda língua, historicamente, atribui o fracasso do aprendizado de línguas a vários fatores. Destacam-se a ansiedade no momento da aula de língua estrangeira (ansiedade em cometer erros de gramática e pronúncia, entender o professor, memorizar vocabulário). Outras causas citadas por autores como (GOMES, 1999; CARLESSO, 2018) incluem falta de esforço, falta de motivação, maus hábitos de aprendizado de idiomas e pouca capacidade de aprender idiomas.

Shumaeva (2018) relata que no final da década de 1960, Kenneth Dinklage, da Universidade de Harvard, buscou entender por que alguns dos melhores e mais brilhantes alunos da famosa Universidade de Harvard não foram aprovados nos seus cursos de idiomas. Ele, rapidamente, descartou a falta de esforço, vendo que a maioria desses estudantes estava comprometendo outros conteúdos e seus diplomas, dedicando uma quantidade incomum de tempo e esforço às aulas de idiomas. Da mesma forma, a falta de motivação não era uma causa, pois esses estudantes não podiam se formar sem ter cumprido seus requisitos linguísticos. Com relação à ansiedade, ele descobriu que os alunos o procuravam porque sofriam de extrema ansiedade devido à impossibilidade de concluir com êxito as aulas de idiomas. Como a maioria desses alunos nunca havia falhado em uma aula antes, ele sentiu que a ansiedade, originalmente, não era o motivo do fracasso. Ao questionar esses alunos, o professor Dinklage descobriu que vários estudantes de idiomas com falha haviam sido diagnosticados com dificuldades de aprendizado e haviam superado sua incapacidade por meio de boas aulas e muito trabalho; o curso de língua estrangeira, no entanto, desencadeou os problemas que os alunos pensavam estar por trás deles. Dinklage descobriu, depois de testar, que outros membros do grupo não tinham problemas de aprendizado diagnosticados. Ele considerou que a terceira parte do grupo sofria de uma dificuldade de aprendizado de idiomas, embora Dinklage não tenha encontrado as evidências usuais de problemas durante os testes. É claro que esses alunos não puderam estudar com êxito idiomas estrangeiros enquanto eram excelentes alunos em outras aulas. Então, em uma espécie de experimento vários anos antes do esperado, ele trouxe um estudante de pós-graduação que tinha um irmão deficiente que estava aprendendo a ensinar espanhol a alguns desses alunos em dificuldades, usando bons métodos de ensino e conhecido por pessoas com dificuldades de aprendizagem. Os alunos assim ensinados eram geralmente aprovados nos exames necessários para atender às exigências estrangeiras. 
Assim, há quase 30 anos, o professor Dinklage identificou a maioria das ideias e princípios básicos relacionados a línguas estrangeiras e dificuldades de aprendizagem: o problema estava relacionado ao fato de o processo de ensino-aprendizagem ser inadequado e não a uma falta de motivação, esforço ou ansiedade. A ansiedade foi o resultado do fracasso, não a causa.

\section{Psicopedagogia para ajudar Crianças com Deficiência aprender um Idioma}

Sabe-se que as contribuições da Psicopedagogia são de extrema importância para uma nova forma de pensar, sentir e agir frente aos conteúdos e no sentido de auxiliar nos processos de ensino- aprendizagem dos alunos, de suas dificuldades e facilidades que, articulados no conjunto, configuram a identidade da comunidade escolar.

Os autores Ganschow e Sparks (1995), estudaram maneiras de ajudar alunos com deficiência a aprender uma língua estrangeira, dentre as quais se destacam duas abordagens:

A primeira e mais estudada abordagem é uma resposta às conclusões de que muitos estudantes com problemas de aquisição de língua estrangeira têm déficits fonológicos na língua materna e defendem que, para ajudar esses alunos, o sistema de som da língua-alvo deve ser ensinado de maneira muito explícita. Para testar essa teoria, os autores colaboraram com um professor de espanhol do ensino médio que havia ensinado o método Orton-Gillingham de ensino de fonologia, leitura e ortografia para alunos com deficiências graves que estavam aprendendo. Nesse método, os sons são apresentados de maneira muito estruturada, com muita prática visual, cinestésica e tátil. A professora de espanhol Karen Miller testou a eficácia do ensino de espanhol para alunos com deficiência usando a abordagem de Orton-Gillingham. A pesquisa com seus alunos mostrou de maneira bastante conclusiva que os estudantes com deficiência foram capazes de aprender e mantê-lo. Outro colaborador, Elke Schneider, obteve resultados semelhantes no ensino de alemão para estudantes com deficiência.

Robles-Castro (2018), relata em seu atual trabalho, o caso de uma menina de 7 anos de idade, diagnosticada com dislexia e dislalia, fato que afeta o seu processo de alfabetização. Dois planos foram desenvolvidos nos quais a metodologia multissensorial focada no desenvolvimento de atividades com o método Orton Gillingham foi usada. Na maioria dos casos, crianças com essa dificuldade de aprendizado apresentam altas taxas de desmotivação e falta de interesse ao aprender e executar atividades que requerem concentração e participação ativa nas atividades de ensino e aprendizagem. Devido à metodologia utilizada, foram projetadas experiências educacionais trabalhadas a partir do visual, auditivo e cinestésico que permitiram ao aluno trabalhar, de maneira lúdica, os tópicos relacionados especificamente à leitura e à escrita. Utilizou-se material concreto como: piano (instrumento musical) para trabalhar a parte auditiva, lendo folhas com imagens usando como guia o método de leitura da escrita Troncoso, uma máquina de palavras desenvolvida por ela, a fim de encontrar novas palavras de uma maneira divertida e atraente.

Enquanto estudavam os alunos de Karen Miller, Ganschow e Sparks (1995) descobriram que, adquirindo habilidades fonológicas em um idioma, os alunos também aprimoravam sua consciência fonológica em outro idioma. Essa observação levou a uma variação no método de ensino de fonologia na língua-alvo: ensinar o básico de fonologia na língua materna do aluno antes do início do ensino de uma língua estrangeira. Ou seja, os alunos aprendem a reconhecer fonemas, decodificar ou ler palavras de maneira eficaz e a codificar ou aplicar sons à linguagem escrita. Basicamente, eles aprendem qual é o idioma e como funcionam seus sons e partes. Aplicar esse conhecimento ao idioma que eles estão tentando aprender é o próximo passo. De fato, Ganschow e Sparks recomendam fortemente que essas habilidades fonológicas e reconhecem que 
são estressantes quando as crianças aprendem a ler. Eles acreditam que as habilidades de leitura e linguagem dos alunos serão muito mais fortes e que muitos dos problemas de aquisição de línguas estrangeiras no futuro serão eliminados.

A segunda abordagem relacionada ao ensino de idiomas, na visão dos autores supracitados, é a adaptação às aulas de idioma estrangeiro aos princípios de ensino conhecidos por serem eficazes para os alunos com deficiência. Isso envolve fazer alterações, como reduzir o programa ao essencial, diminuir o ritmo da instrução, reduzir a demanda por vocabulário, revisão constante e incorporar estímulo máximo e suporte visual / tátil / cinestésico, ou seja, multissensorial. Muitas dessas adaptações do curso também foram respostas a reclamações e solicitações específicas de estudantes de línguas estrangeiras com problemas na sala de aula. Além disso, em algumas escolas, existem cursos projetados para estudantes que são bons em ouvir e falar, mas que são fracos em leitura e escrita e vice-versa GANSCHOW E SPARKS (1995).

No contexto escolar, o psicopedagogo tem uma importância incalculável. É a partir de um estudo mais amplo e profundo que se identificam possíveis problemas, dificuldades, mas também facilidades e fortalezas no processo de aprendizagem. Dessa forma, o profissional consegue decifrar os processos que levam o ser humano a aprender.

\section{A prática - e se essas condições de ensino não puderem ser aplicadas e cumpridas?}

Na prática, deve-se pensar que a participação de alunos com deficiência ainda se destacam dois problemas:

O primeiro é que é raro que uma escola esteja disposta a dedicar um espaço ou aulas inteiras de línguas estrangeiras aos estudantes com deficiência, ou seja, criar um programa específico. A segunda é encontrar professores dispostos e treinados para ensinar uma língua estrangeira a estudantes com deficiência.

Na maioria das vezes, no mundo real, os estudantes com deficiência se encontram em uma sala de aula dos chamados alunos "normais" ou no conhecido "ensino regular". Nesse caso, os alunos podem contar com a disposição do professor de ser criativo e flexível, bem como com a escola ou o próprio sistema escolar para adaptar o aluno às suas habilidades e exigências da lei. É quase igualmente doloroso quando um professor reconhece as necessidades de um aluno em particular, mas não tem tempo, recursos e nem apoio para poder atender adequadamente às suas necessidades.

Como em qualquer aspecto do processo de ensino e aprendizagem de um aluno com deficiência, nenhuma solução é única e adequada para todos. Existem muitas histórias de alunos com deficiência que aprenderam uma língua estrangeira de uma maneira ou de outra. A pergunta a se fazer, no entanto, é o que esse "aprender" significa? O que esse aprender pode contribuir e trazer de positivo para a vida do aluno? Os alunos podem se tornar conversadores com sotaques excelentes, mesmo mantendo-se bastante limitados em gramática e linguagem escrita. Outros podem ser leitores muito proficientes de uma língua, enquanto praticamente não conseguem conversar além das frases mais elementares. Outros ainda podem ser bastante proficientes em todas as áreas, mas nunca alcançam um sotaque do idioma nativo no idioma estrangeiro.

Consequentemente, quando um aluno com deficiência enfrenta a aprendizagem de uma língua estrangeira, deve ser realizada uma avaliação realista de sua situação, seus limites, seus problemas e suas reais necessidades por uma equipe multidisciplinar. 
Portanto, como em várias circunstâncias relacionadas à deficiência, as respostas são muitas vezes complexas e de longo prazo, e o problema e a solução para cada aluno podem ser diferentes. O mais importante é que o problema de aprender idiomas estrangeiros para pessoas com deficiência seja reconhecido pelo que é e que o aluno seja acomodado de maneira justa e razoável. Felizmente, à medida que os profissionais da área da educação, da saúde conscientizarem da importância de pesquisas e referenciais de literatura, a jornada do estudante com deficiência, que tem o direito de aprender uma língua estrangeira, se tornará mais fácil.

\section{Considerações finais}

Familiares, psicopedagogos, profissionais da área educação, da saúde devem ser tradutores dos contextos individuais e subjetivos de jovens com deficiência, quando necessário. Para que isso ocorra deve-se pensar na comunicação da família alinhada com a escola e, a escola, por sua vez, alinhada com o jovem. Lembrando que a escola não é importante apenas para a socialização da criança com deficiência, mas também para a sua constituição como sujeito.

É possível perceber em nossa atualidade as dificuldades referentes às interações de comunicações e linguagem, num contexto geral. Temos problemas de comunicação desde redes sociais, no âmbito familiar, educacional, bem como no âmbito da saúde.

O educador deve estar empenhado à rotina de seus alunos para promover eventos onde todos possam participar de atividades. Na interação e comunicação em de sala de aula, o professor deve estar atento para a função da fala no processo da aprendizagem da leitura e da escrita, por exemplo, quando se estuda uma língua de natureza alfabética, como a língua portuguesa. Entender como se processa a aquisição de um idioma e da função da fala entra a função de complexidade maior, que é a linguagem.

A linguagem é uma função mental superior que possibilita compreender informações do ambiente através dos canais sensoriais e, em seguida, a pessoa pode processar esses estímulos recebidos nas diferentes regiões cerebrais. Os profissionais que atuam com pessoas com deficiência precisam compreender sobre a aquisição e do desenvolvimento da linguagem, suas diferentes possibilidades de como a pessoa com deficiência expressa seus desejos, seus sentimentos, suas intenções e crenças.

É fundamental, portanto, profissionais dispostos e competentes para as linguagens, pois as pessoas com deficiência sentir-se-ão motivadas mesmo diante de currículos adaptados.

Sublinha-se que a deficiência não é algo que surge com o nascimento de alguém ou com a enfermidade que alguém contrai, mas é produzida e mantida por um grupo social na medida em que esse mesmo grupo interpreta e trata as diferenças apresentadas por determinadas pessoas. Ninguém melhor que o psicopedagogo para equilibrar e mediar tais processos.

\section{Referências}

BARR, Vickie. "Conditions requises pour les langues étrangères et les étudiants ayant des troubles d'apprentissage" ERIC Digest. 1993. ED355834.

CARLESSO, Simone. A interculturalidade como fator motivacional no aprendizado de língua inglesa. 2018. Disponível em: http://repositorio.utfpr.edu.br/jspui/handle/1/18985. 
DEMUTH, Katherine A.; SMITH, Nathaniel B. "L'exigence de langue étrangère: un programme alternatif." The Foreign Annals 20, 1987, p 66-77.

DIAS, Juliana Teixeira; LEVENTHAL, Lilian Itzicovitch. Práticas inclusivas e o Ensino de Inglês: um guia para professores de línguas estrangeiras e educação bilíngue. Editora Dialética, 2021.

DINKLAGE, David Kenneth. "Incapacité d’apprendre une langue étrangère" dans G. Blaine \& C. MacArthur (Eds.) Problèmes émotionnels de l'étudiant. New York, 1971: Appleton-Century-Crofts.

GANSCHOW, Leonore; SPARKS, Richard; SCHNEIDER, Elke. "Apprendre une langue étrangère: Défis pour les étudiants ayant des difficultés d'apprentissage linguistique." Dyslexie, Journal de la British Dyslexia Association, 1, (1995): 75-95.

GANSCHOW, Leonore et Richard Sparks. "Effets de l'enseignement direct en phonologie espagnole sur les compétences en langue maternelle et l'aptitude en langue étrangère des apprenants en langue étrangère à risque." Journal of Learning Disabilities 28, (1995): 107-120.

GÓMEZ, Pascual Cantos. A motivação no processo ensino/aprendizagem de idiomas: um enfoque desvinculado dos postulados de Gardner e Lambert. Trabalhos em Linguística Aplicada, v. 34, 1999.

HAAG, Cassiano Ricardo. Deficiência Intelectual - Por uma perspectiva da linguagem em interação. Tese de Doutorado. São Leopoldo/RS: UNISINOS, 2015.

HILL, Barbara et al. "Répondre aux besoins des étudiants ayant de graves difficultés d'apprentissage des langues dans des classes de langues étrangères modifiées." Dans G. Grouse, (Ed.), Elargir les frontières de l'enseignement des langues. Lincolnwood, IL, 1995: National Textbook Co.

KEYSAR, Boaz; HAYAKAWA, Sayuri; AN, Sun Gyu. The foreign-language effect: Thinking in a foreign tongue reduces decision biases. Psychological science, v. 23, n. 6, p. 661-668, 2012.

KOBOLT, Maria Edilene de Paula; MIRA, Ane Patrícia Viana José de. Deficiência Intelectual e o Ensino-Aprendizagem de Língua Espanhola: O Desafio Entre Linguagens. 2015 Disponível em http://www.Gestaouniversitaria.Com.Br/System/Scientific_Articles/Files/000/000/493/ Original/Defici\%C3\%8ancia_Intelectual_E_O_Ensino-Aprendizagem_De_L\%C3\%8dngua_ Espanhola_O_Desafio_Entre_Linguagens..Pdf?1554256822. Acesso em 15/02/2021.

ROONEY, Karen. “La dyslexie revisitée: applications de l'histoire, de la pédagogie et de l'évaluation clinique." Intervention in School and Clinic 31, 1995, p. 6-15.

SPARKS, Richard; GANSCHOW, Leonore. "L'impact des problèmes d'apprentissage des langues autochtones sur l'apprentissage des langues étrangères: illustrations de l'hypothèse du déficit de codage linguistique." Modern Language Journal 77, i (1993): 58-74.

VOGEL, Susan; ADELMAN, Pamela. Succès pour les étudiants en difficulté d’apprentissage. New York, 1993: Springer Verlag.

ROBIN, Lovrien Schwarz. Troubles du savoir Spécialiste en langues Coordonnateur du programme de compétences en apprentissage. The English Language Institute, Université américaine de Washington, octobre 1997. 
RESUMO ESCOLAR. Copyright (C 2019. Linguagem e Comunicação. Resumo Escolar. Disponível em: https://www.resumoescolar.com.br/portugues/linguagem-e-comunicacao/ Acesso em: 16/02/2020.

RICALDI, Tiago Anunciação; BERKENBROCK, Carla Diacui Medeiros. Elicitação de requisitos para promover a comunicação de crianças com deficiência intelectual. Revista Brasileira de Computação Aplicada, v. 13, n. 1, p. 125-133, 2021.

LELO, Thales Vilela. Faces do comum na comunicação: da partilha à disjunção. Galáxia. Revista do Programa de Pós-Graduação em Comunicação e Semiótica. ISSN 1982-2553, n. 31, 2016.

ROBLES CASTRO, Lady Stephanie. El método Orton Gillingham en el desarrollo del proceso de lectoescritura en una niña con dislexia. 2018. Disponível em: http://repositorio.ucsg.edu.ec/ handle/3317/11633. Acesso em: 10/02/2021.

SHUMAEVA, Svitlana. TO THE QUESTION OF DISABILITIES OF FOREIGN LANGUAGES MASTERING. Збірник тез доповідей [Електронний ресурс] II Міжнародної науковопрактичної інтернет-конференції «Іноземна мова у професійній підготовці спеціалістів: проблеми та стратегії».-Кропивницький: РВВ цДПУ ім. В. Винниченка, 2018.-192 с., p. 101, 2018.

SEVERINO Antônio Joaquim. Metodologia do trabalho científico. 22a ed. São Paulo: Cortez; 2002. 